\title{
Abdominal cavity simulator for skill progression in videolaparoscopic sutures in Brazil ${ }^{1}$
}

Francisco Ferreira Filho', Luiz Gonzaga de Moura Júnior", Hermano Alexandre Lima Rocha'", Sabrina Gabriele Maia Oliveira Rochalv, Lucas Fortes Portela Ferreirav, Amanda Fortes Portela FerreiraVI

'MD, Centro Universitário Unichristus, Fortaleza-CE, Brazil. Conception, design and intellectual content of the study; critical revision; approved the final version.

"PhD, Centro Universitário Unichristus, Fortaleza-CE, Brazil. Conception, design and intellectual content of the study; critical revision; approved the final version.

I'PhD, Community Health Department, Universidade Federal do Ceará (UFC), Fortaleza-CE, Brazil. Conception, design and intellectual content of the study; critical revision; approved the final version.

IVMD, Community Health Department, UFC, Fortaleza-CE, Brazil. Conception, design and intellectual content of the study; critical revision; approved the final version.

${ }^{\vee}$ MD, Universidade Federal do Cariri (UFCA), Juazeiro do Norte-CE, Brazil. Intellectual content of the study, analysis and interpretation of data, critical revision, approved the final version.

${ }^{\mathrm{V}} \mathrm{MD}$, Centro Universitário Unichristus, Fortaleza-CE, Brazil. Intellectual content of the study, analysis and interpretation of data, critical revision, approved the final version.

\section{Abstract}

Purpose: To develop and test a model of teaching by means of an abdominal cavity simulator. Methods: This study had two stages: development of a teaching model and an experimental prospective study that aimed to evaluate the residents' competence. The participants were divided into 3 groups: first-year resident, second-year resident, and senior surgeon. The two groups of resident physicians received training in the simulator, under instructor supervision for skill acquisition, according to the model proposed in first stage. The surgeons did not receive this intervention. The correlations and associations were verified through simple and multiple linear regressions. The learning curves were analysed using Cox regression models. The impact of the epidemiological characteristics was tested.

Results: All residents reached the maximum score at the end of 16 steps and were comparable to the experimental $(p<0.001)$.

Conclusion: Residents who underwent training using the methodology of the proposed teaching model, which is based on realistic simulation, acquired proficiency in the accomplishment of endosutures in up to 16 hours of training in the laboratory.

Key words: Laparoscopy. Education. Simulation Training. Surgical Procedures, Operative. 


\section{Introduction}

Simulation is a training method used mainly in risk activities, with the aim of increasing the safety of the procedures. In the area of healthcare, it aims to reproduce the essential aspects of a clinical scenario, increasing the possibility of success in a real clinical context ${ }^{1}$. Realistic simulation has emerged as a tool for learning in video surgery, performed in an accessible, safe, controlled and standardized environment, which aims to improve skills and transfer them to the operating room, promoting an increase in the learning curve ${ }^{2}$.

The growing ethical need for greater patient safety has stimulated the development and validation of simulators as a teaching tool in the skills laboratories of several institutions ${ }^{2}$. The use of simulators can be applied at different levels of professional training: during the specialty years, in the postgraduate period, and in the maintenance of certain previously acquired skills in professionals ${ }^{3}$.

Complex laparoscopic tasks, such as laparoscopic sutures and intracorporeal knots, require a high level of technical skill. This can be achieved through the use of a simulation model ${ }^{4}$. The performance of video surgeries by resident physicians considerably increases surgical time and hospital stay ${ }^{5}$. The practice of physicians learning advanced laparoscopic procedures in the operating room is insufficient for proficiency in advanced techniques. This emphasizes the importance of training in the laboratory before the operating room, with the aim of improving learning ${ }^{6}$. Buckley et al. ${ }^{4}$ have consistently documented the positive impact of the simulation on operative time, although the data are insufficient to demonstrate the transfer of these skills to the operating room. Choy et al. ${ }^{7}$ have shown that training with simulators improves residents' ability to perform advanced procedures and the safety of residency programmes.
Considering that there are few well-designed teaching models that were proven to be effective in the preparation of resident physicians for advanced laparoscopic techniques outside the operating room, this paper sought to develop and test a model of teaching by means of an abdominal cavity simulator for the progression of skills in videolaparoscopic endosutures.

\section{Methods}

The research was analysed and approved by the Research Ethics Committee (REC) of Centro Universitário Unichristus and Instituto Dr. José Frota (Protocol of REC 59774116.20000.5049), in compliance with Resolution 466/12 of the National Health Council. The research was processed according to the release of the approved consent opinion and after free and informed consent of the group studied by participant in which they expressed their consent to participate in the research.

\section{Study type and population}

This study was divided in two stages: the first was the development of a teaching model that uses abdominal cavity simulators to acquire proficiency in videolaparoscopic endosutures, employing the scientific literature and proposing interventions. At this stage, there were no human trials. The Psychomotor Skills Progression Scale and Suture Proficiency in Video Surgery was developed as an initial reference for psychomotor skills developed by Moura Júnior 5 .

The second stage was an experimental prospective study that aimed to evaluate the residents' competence in the progression of their abilities to execute tasks using the proposed teaching model. In this stage, the participants were divided into 3 groups with 10 components each: first-year resident physicians 
(R1), second-year resident physicians (R2), and senior surgeon preceptors of surgery. The two groups of resident physicians received training in the simulator. Resident physicians R1 and R2 conducted two weekly sessions of training in video simulator surgery under instructor supervision for skill acquisition (ergonomics, laparoscopic forceps handling, stereotactic, triangulation, core effect, ambidexterity, hapticity, handles, strings, adjusted knots and endosutures), according to the model proposed in step 1 . The training sessions lasted two hours. The surgeons did not receive this intervention.

The competence of $\mathrm{R} 1$ and $\mathrm{R} 2$ in the execution of the endosutures was evaluated longitudinally. Residents who were able to complete the six points with five adjusted knots within 18 minutes had their training terminated after suture analysis by the investigator, confirming that all qualitative criteria were met. The training was completed when the endorsed study reached two points in the evaluation of the researcher, as shown in Table 1.

The senior surgeons performed suturing with at least six points with five adjusted knots. Surgeons who achieved the goal in shorter time continued to suture until they completed eighteen minutes.

Table 1 - Study criteria used for evaluate the acquiring proficiency.

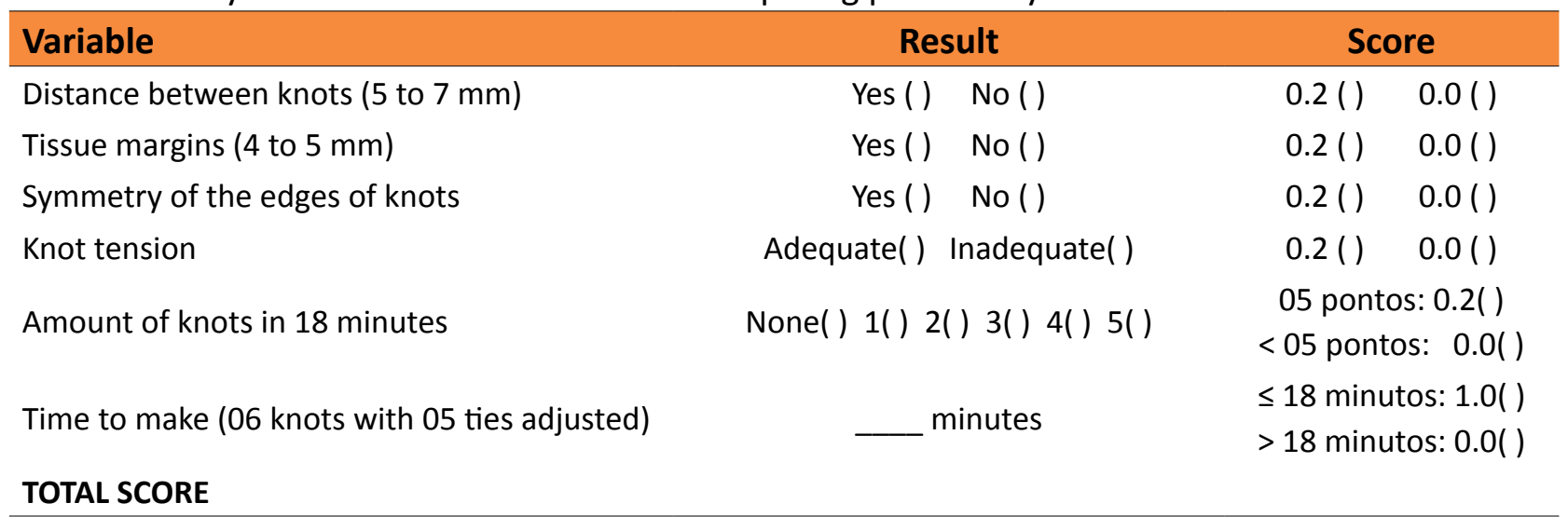

Study site

Previous training and evaluation of surgical residents occurred in the Surgical Skills Laboratories, Centro Universitário Unichristus, and Instituto Dr. José Frota, from February to September 2016. Unichristus' SSL is housed in a $40 \mathrm{~m}^{2}$ air-conditioned room with fluorescent lighting. It has 08 EndoSuture Trainer Box ${ }^{\circ}$ simulators distributed at a distance of 1.0 metres from each other, with 08 support benches, consumer surgical materials (threads, gloves, tissue substitutes, forms) and permanent instruments (tweezers, needle holders and laparoscopic scissors). José Frota Institute's SSL is installed in an air-conditioned room in the Study Center, measuring $50 \mathrm{~m}^{2}$, with fluorescent ceiling lighting. It has 02 Endo-Suture Trainer Box simulators installed at a distance of 1.5 metres between them, two benches and a support table.

\section{Study sample}

The sample consisted of 10 resident physicians of first-year general surgery (R1), 10 second-year general surgery residents (R2) and 10 senior surgeons, a sample compatible with studies published in the international literature.

Intervention group: Residents of general surgery (R1 and R2) in the state of 
Ceará enrolled in the Dr José Frota Institute (IJF) on duty for a minimum of 30 days between February and September 2016 were included in the sample. Residents who did not complete the training, those who did not follow the proposed model of endorsement, and those who were on leave or leave during the training period were excluded from the study.

Comparative group: Surgeons employed at the $\mathrm{Dr}$ José Frota Institute who have performed at least 50 advanced videolaparoscopic surgeries (fundoplication and/or endosuture digestive procedures) and who have performed more than 50 hours of videolaparoscopic procedures per year. Surgeons who were on leave or leave during the study period were not included in the sample.

\section{Study variables}

We used epidemiological variables of the first- (R1) and second-year (R2) residents who measured the level of previous experience with videolaparoscopic procedures. For both groups of residents and senior surgeons, we used categorical variables that assessed the quality of the suture and numerical variables that measured the level of ability and the time to perform the endosutures, as described below:

\section{Categorical variables}

a) Variable "distance between points": All six knots must maintain between them a distance between 5 and $7 \mathrm{~mm}$. The pointer scored 0.2 points. If any knots were outside the standardized distance, the participant received a zero score. The assessment was made by the researcher.

b) Variable "tissue margin of knots": All six knots should have a lateral tissue margin to suture between 4 and $5 \mathrm{~mm}$. The indicator was worth 0.2 points. If any knots were outside the standardized range, the participant would receive zero. c) Variable "border symmetry": The six knots should maintain symmetry at the depth of the left and right edges of the suture. The acceptable difference was less than $1 \mathrm{~mm}$. This item equals 0.2 points. If any knots were out of standardized symmetry, the score would be zeroed.

d) Variable "knot tension": The six knots should have adequate tension, keeping the edges of the suture together. The indicator was worth 0.2 points. If any points were out of standardized tension, the score would be zero. The gauging was performed by the researcher with the removal of all points using laparoscopic scissors. The tip of the scissors was inserted into the point handle, allowing a unique cut.

The measurements of each item were made by a experienced surgeon (more than 80 surgeries), through blinded recordings of the procedures performed by the participants, after the end of the procedure, and by only on judge to guarantee standardization.

Numerical variables

a) Variable "number of knots in 18 minutes": at least five knots should be performed in 18 minutes. The indicator was worth 0.5 points. If less than five knots were performed at the standard time, the score would be zero. The assessment was made by the researcher.

b) Variable "time to make the suture" (06 points with 05 knots adjusted): The six knots should be performed in a time equal to or less than 18 minutes. The indicator was worth 1.0 point. If the six points were accomplished in a longer time than standardized, the score would be zero. The assessment was made by the researcher.

c) Variable "sum of skills": Represented the sum of all categorical and numerical variables. This variable defined the level of skill in making the suture. When the sum was equal to 2.0 points, it was considered that the student had reached proficiency. 


\section{Acquisition of proficiency}

The competence of the residents in the execution of the sutures was evaluated longitudinally. The training was completed when the suture earned two points according to the researcher's evaluation. The criteria used to consider the proficient trainee are listed in Table 1.

\section{Development of the teaching model}

The developed model was composed of theoretical and practical activities aimed at the acquisition of psychomotor skills in basic and advanced video surgery. The training sessions were performed in Surgical Skills Laboratories using abdominal cavity simulators with structure to simulate laparoscopic procedures. Sessions were monitored by a surgeon. The following materials were used in the laboratory of surgical skills: abdominal cavity simulators, surgical instruments, thread, rubber pieces, and other materials. Chart 1 summarizes the training steps.

Chart 1 - Study stages of training and evaluation of the surgical skills of residents of surgery.

\begin{tabular}{|c|c|}
\hline $\begin{array}{l}\text { FASE I } \\
\text { Theoretical-practical explanation }\end{array}$ & $\begin{array}{l}\text { - Fundamentals of Video Surgery } \\
\text { - Differences between conventional method and video-surgery } \\
\text { - Role of the Laboratory of Surgical Skills (LHC) in teaching } \\
\text { - Introduction of concepts and skills } \\
\text { - Demonstration of training steps } \\
\text { - Session of surgical videos about the teaching model } \\
\text { - Visit to the Laboratory of Surgical Skills }\end{array}$ \\
\hline Training for acquisition of psychomotor skills & $\begin{array}{l}\text { - Ergonomics } \\
\text { - Handling of laparoscopic forceps } \\
\text { - Stereotaxia } \\
\text { - Triangulation } \\
\text { - Core effect } \\
\text { - Ambidextrous } \\
\text { - Hapticity } \\
\text { - Strap top } \\
\text { - Threaded wire } \\
\text { - We adjusted } \\
\text { - Surgical Video Sutures }\end{array}$ \\
\hline Transfer of objects & $\begin{array}{l}\text { - With the right hand forwards (aheadhand) } \\
\text { - With the right hand back (backhand) } \\
\text { - With the left hand forward (aheadhand) } \\
\text { - With the left hand back (backhand) }\end{array}$ \\
\hline Strap loop & $\begin{array}{l}\text { - Anterograde loop } \\
\text { - Retrograde loop }\end{array}$ \\
\hline Thread loop & $\begin{array}{l}\text { - Right to left } \\
\text { - Left to right }\end{array}$ \\
\hline Making knots & $\begin{array}{l}\text { - Non-instrumental footprint } \\
\text { - Footprint on the wire } \\
\text { - Wire size } \\
\text { - Footprint on needle } \\
\text { - Needle thread and surgical thread } \\
\text { - Surgical Fittings: Letter C and Letter D fomat }\end{array}$ \\
\hline Making sutures & $\begin{array}{l}\text { - Distance between knots } \\
\text { - Tissue margin of knots } \\
\text { - Symmetry of edges } \\
\text { - Tension of knots }\end{array}$ \\
\hline
\end{tabular}




\section{Data processing and analysis}

The numerical and categorical variables used as parameters to acquire proficiency in the endosutures were analysed in the pre-test and in the post-tests. Categorical quantitative results were presented as percentages and counts, and the numerical results were measured as central trend measures. A comparison test was performed on the binomial distribution of a sample to test the main hypothesis. ANOVA and chi square tests were performed to compare variables, as appropriate. The correlations and associations between two numerical variables were verified through simple and multiple linear regression, when the determinants were included in addition to the number of training sessions. Comparisons with $p$ value up to 0.05 were considered significant. The learning curves were analysed longitudinally using Cox regression models. The impact of the epidemiological characteristics on the learning curve was tested. The qualitative data were transformed by a Likert scale for quantitative gauging. The data were tabulated and analysed by SPSS software (Statistical Package for the Social Sciences), v23, SPSS, Inc. for the analysis and evaluation of data collected.

\section{Results}

\section{Evolution of learning}

Table 2 shows the number of tests required to obtain the maximum score for residents. The average knots made in 18 minutes were 2 knots in the pre-test and increased to 6 points in the last test. The average suture length increased from 45.9 minutes to 18 minutes from the pre-test to the last test. The mean final score evolved from 0.2 in the pre-test to 2.0 in the final test. The $\mathrm{p}$-value of the main hypothesis test was 0.012 .

Table 2 - Total tests performed by surgical residents to reach the maximum score, for each criterion evaluated.

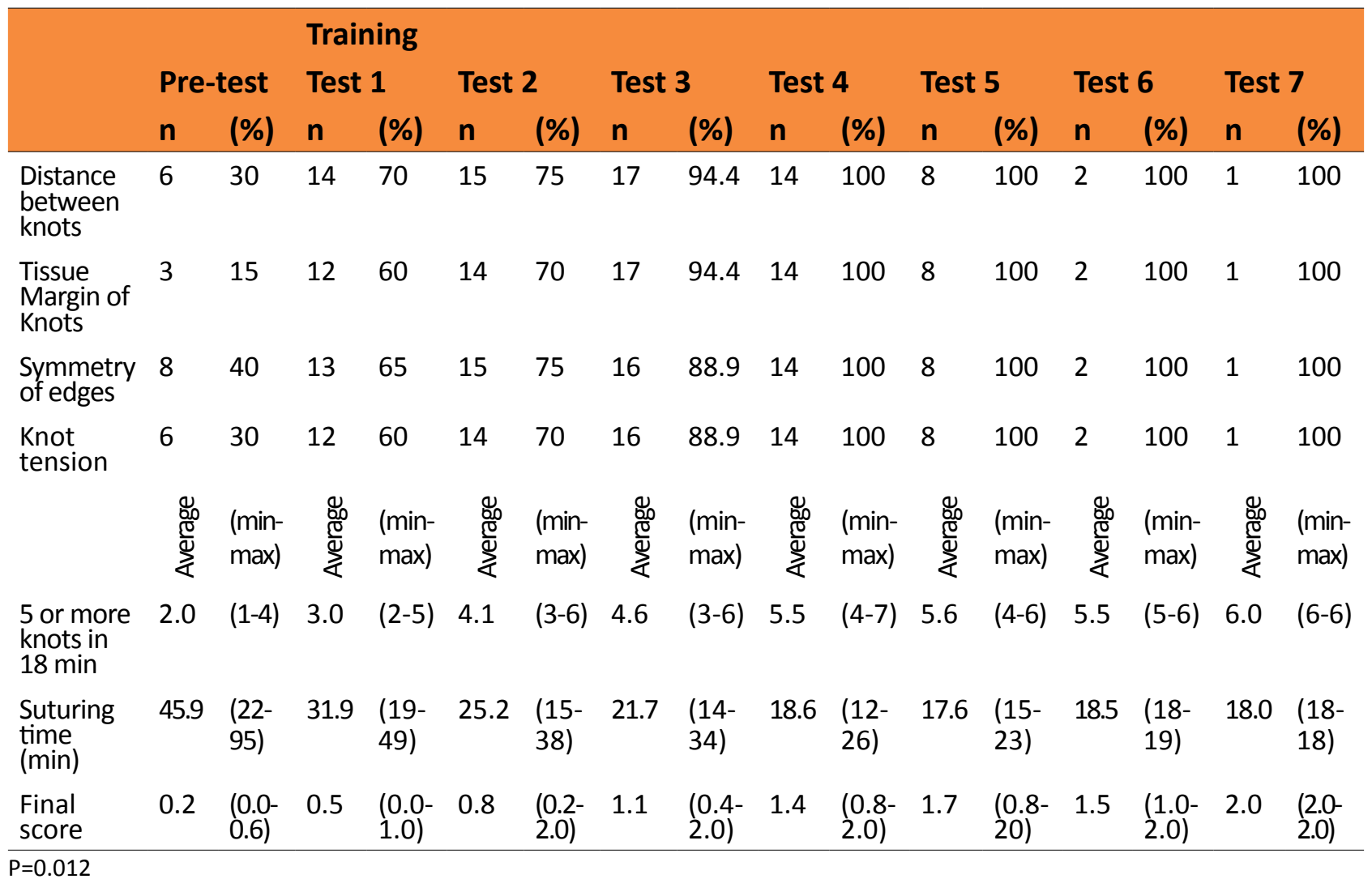


Tables 3 and 4 show the comparison of the skills between R1 and R2 in the pre-test and after the last test, along with comparisons with the results of the surgeons.

Table 3 - Comparison of skills, in the pre-test and after the last training test, among first (R1) and second (R2) year surgical residents of IJF Institute.

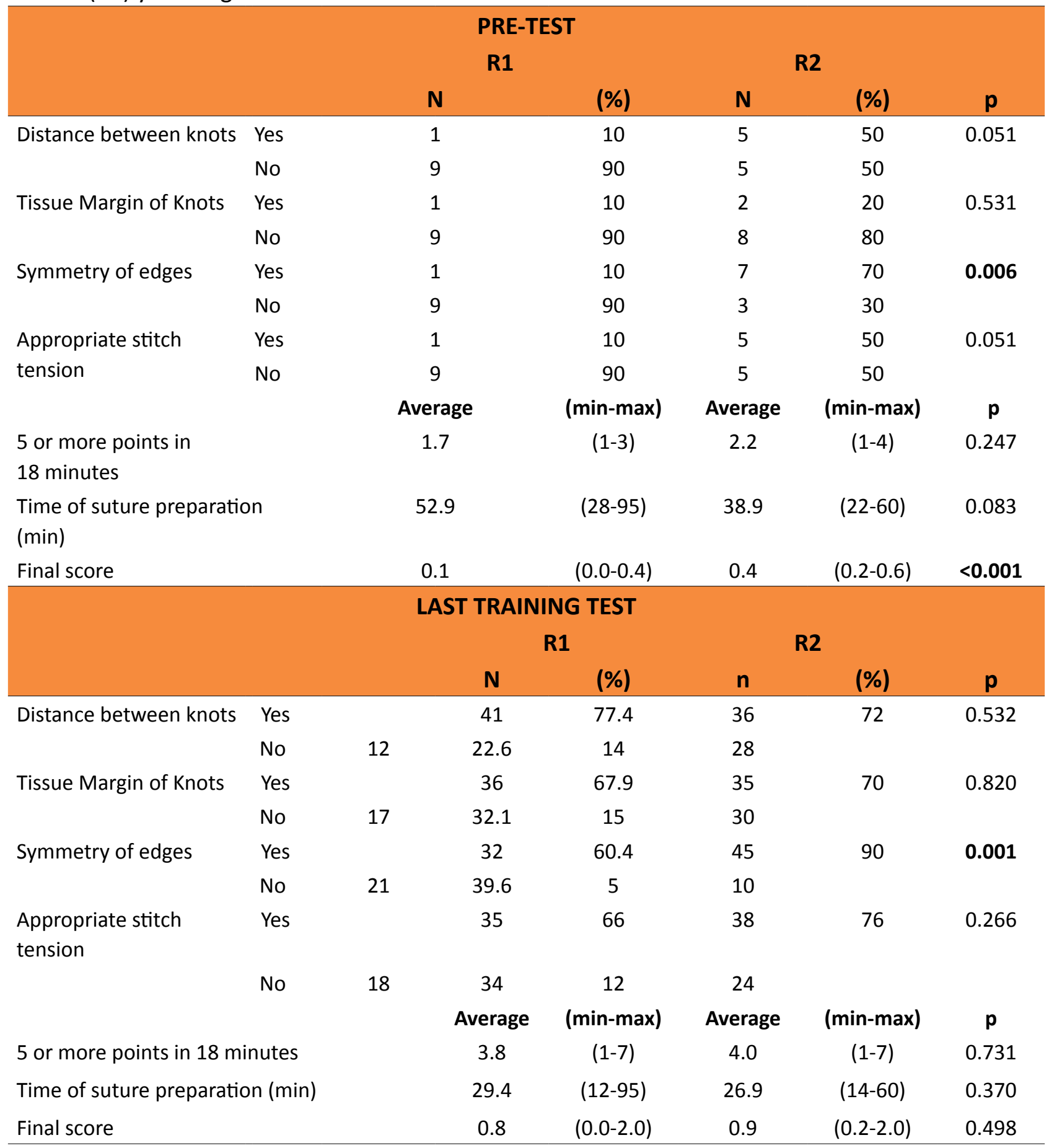


Table 4 - Comparison of skills, in the pre-test and after the last training test, between the residents of the second year of surgery and the senior surgeons of IJF Institute.

\begin{tabular}{|c|c|c|c|c|c|c|}
\hline \multicolumn{7}{|c|}{ PRE-TEST } \\
\hline & & \multicolumn{2}{|c|}{$\mathbf{R 2}$} & \multicolumn{2}{|c|}{ Senior surgeons } & \multirow[b]{2}{*}{$p$} \\
\hline & & n & (\%) & $\mathbf{n}$ & (\%) & \\
\hline \multirow[t]{2}{*}{ Distance between knots } & No & 5 & 50 & 0 & 0 & 0.010 \\
\hline & Yes & 5 & 50 & 10 & 100 & \\
\hline \multirow[t]{2}{*}{ Tissue Margin of Knots } & No & 8 & 80 & 0 & 0 & $<0.001$ \\
\hline & Yes & 2 & 20 & 10 & 100 & \\
\hline \multirow[t]{2}{*}{ Symmetry of edges } & No & 3 & 30 & 0 & 0 & 0.060 \\
\hline & Yes & 7 & 70 & 10 & 100 & \\
\hline \multirow[t]{3}{*}{ Appropriate stitch tension } & No & 5 & 50 & 0 & 0 & 0.010 \\
\hline & Yes & 5 & 50 & 10 & 100 & \\
\hline & & Average & (min-max) & Average & $(\min -\max )$ & $\mathbf{P}$ \\
\hline \multicolumn{2}{|c|}{5 or more points in 18 minutes } & 2.2 & $(1-4)$ & 6.6 & $(4-9)$ & $<0.001$ \\
\hline \multicolumn{2}{|c|}{ Time of suture preparation (min) } & 38.9 & $(22-60)$ & 16.0 & $(10-24)$ & $<0.001$ \\
\hline \multicolumn{2}{|l|}{ Final score } & 0.4 & $(0.2-0.6)$ & 1.8 & $(0.8-2.0)$ & $<0.001$ \\
\hline \multicolumn{7}{|c|}{ LAST TRAINING TEST } \\
\hline & & \multicolumn{2}{|r|}{ R2 } & \multicolumn{2}{|c|}{ Senior surgeons } & \\
\hline & & n & (\%) & n & $(\%)$ & p \\
\hline \multirow[t]{2}{*}{ Distance between knots } & No & 14 & 28 & 0 & 0 & 0.056 \\
\hline & Yes & 36 & 72 & 10 & 100 & \\
\hline \multirow[t]{2}{*}{ Tissue Margin of Knots } & No & 15 & 30 & 0 & 0 & 0.046 \\
\hline & Yes & 35 & 70 & 10 & 100 & \\
\hline \multirow[t]{2}{*}{ Symmetry of edges } & No & 5 & 10 & 0 & 0 & 0.296 \\
\hline & Yes & 45 & 90 & 10 & 100 & \\
\hline \multirow[t]{3}{*}{ Appropriate stitch tension } & No & 12 & 24 & 0 & 0 & 0.083 \\
\hline & Yes & 38 & 76 & 10 & 100 & \\
\hline & & Average & (min-max) & Average & (min-max) & $\mathbf{p}$ \\
\hline \multicolumn{2}{|c|}{5 or more points in 18 minutes } & 4.0 & $(1-7)$ & 6.6 & $(4-9)$ & $<0.001$ \\
\hline \multicolumn{2}{|c|}{ Time of suture preparation (min) } & 26.9 & $(14-60)$ & 16.0 & $(10-24)$ & 0.003 \\
\hline \multicolumn{2}{|l|}{ Final score } & 0.9 & $(0.2-2.0)$ & 1.8 & $(0.8-2.0)$ & $<0.001$ \\
\hline
\end{tabular}

The comparison of pre-test skills among first- and second-year residents revealed a statistically significant difference in the edge symmetry and final score, with the superiority of second-year residents. Edge symmetry was better performed by $R 2$ in the pre-test $(p=$ $0.006)$ compared to R1. The mean final score of the $R 1$ in the pre-test was 0.1 , while that of $R 2$ was 0.4 and that of the surgeons was 1.8 . In the pre-test, the distance between the knots $(p=$ $(P=0.031)$, tissue margin $(p=0.531)$, adequate knot tension ( $p=0.051)$, number of knots in 18 minutes $(p=0.247)$ and suture preparation time $(p=0.083)$ showed no statistically significant differences between R1 and R2. The $\mathrm{R} 2$ showed a greater ability than the R1 in the 
symmetry criterion of the pre-test edges $(p=$ $0.006)$. It was noted that only $10 \%$ of the R1 was able to correctly perform the distance between the knots, a good tissue margin of the knots, symmetry of the edges and adequate tension of the knots, criteria evaluated in the pre-test. Comparison of skills in the pre-test between R2 and senior surgeons revealed a statistically significant difference in the 5 criteria and in the final score, with superior performance of the surgeons. The distance between the knots $(p=0.010)$, the tissue margin of the knots ( $p$ $<0.001)$, knot tension $(p=0.010), 5$ or more knots in $18 \mathrm{~min}(\mathrm{p}<0.001)$ and suture $(P<0.001)$ were criteria better performed by the surgeons than by the R2, during the pre-test.

In the post test, it was observed that there was only a difference in the symmetry of the edges between R1 and R2. Approximately $90 \%$ of the R2 obtained adequate symmetry, compared with $60.4 \%$ of the R1 ( $p=0.001)$. In the comparison between R2 and surgeons, one criterion, "tissue margin of 4 to $5 \mathrm{~mm}$ knots" ( $p=0.046)$, showed a significant difference in relation to the results of the pre-test.

Figure 1 shows the evolution of the final score reached by residents of IJF surgery throughout the training. All residents studied reached the maximum score at the end of the procedure.

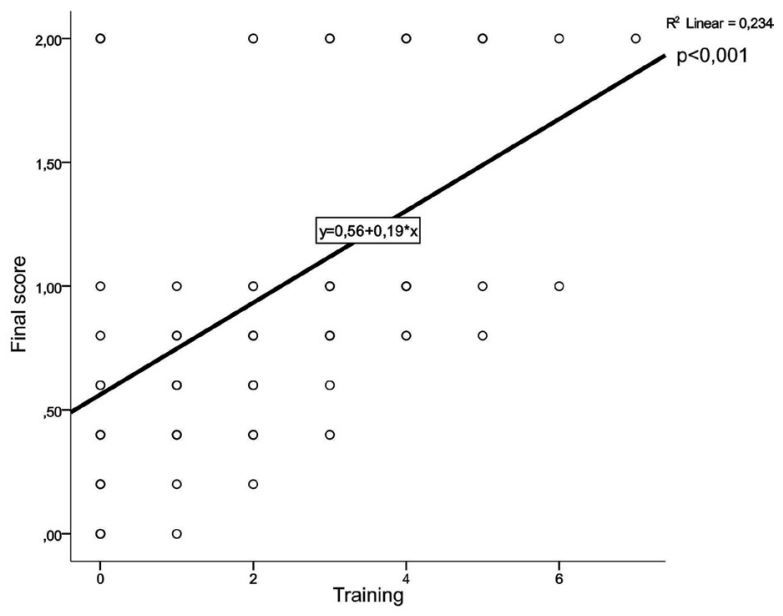

Figure 1 - Final score reached by residents throughout the training.

\section{Discussion}

These results demonstrated that general surgery residents who underwent training in videolaparoscopic simulators using the methodology of the proposed teaching model based on realistic simulation acquired proficiency in the performance of endosutures after up to 16 hours of training in the laboratory. The P-value of the main hypothesis test was 0.012 .

Consistent evidence of the efficacy of simulation as a tool for skill acquisition led the Society of American Gastrointestinal and Endoscopic Surgeons (SAGES) to develop and incorporate into their cognitive curriculum an educational programme entitled Fundamental of Laparoscopic Skills (FSL) in the early 2000s. The training aims to improve and transfer the skills acquired from the training lab to the operating room ${ }^{8}$. The programme consists of laparoscopic training modules in simulators covering pre, intra and postoperative knowledge and basic (object transfer, cut patterns, loop ligatures, knots and extracorporeal sutures) and advanced laparoscopic procedures (intracorporeal knots and sutures), with the measurement of cognitive and technical skills. Korndorffer et al. ${ }^{9}$ studied the transfer of skills from a simulation environment to the operating room. Seventeen residents with basic videolaparoscopy training but with minimal experience in advanced procedures were randomized to undergo training in simulators preceding a laparoscopic Nissen fundoplication in pigs. The group with previous training in simulators performed fundoplication in less time, with a lower overall score and errors $(p<0.001)$, confirming the superior performance compared to the group without the intervention. The author concluded that simulator training is effective in acquiring skills, and these are transferable to the operating room ${ }^{9}$. The data from this study 
reinforce the analysis of the insufficient quality of the endosuture measured in the pre-test of the two groups of residents and in the group of surgeons, where it was verified that only $10 \%$ of first-year residents and $20 \%$ of secondyear residents performed technically suitable sutures. It is noteworthy that most of the R2 were in the last quarter of the residence. In the pre-test, was identified that the skills of residents of different years and surgeons was quite diverse. When comparing the groups of residents and surgeons in the post-test, it was observed that one of the finest variables of the evaluation, the symmetry, was the only point that the least experienced residents had a deficit compared to their second-year peers. Both presented inferior results to the surgeons with regard to the margin of the nodes, demonstrating that the adequate margin has a flatter learning curve. This also suggest the efficacy of the proposed model.

There is a great variety of simulators for training in laparoscopy, with advantages and disadvantages in each model. However, the criteria for proficiency evaluation are quite heterogeneous in the learning studies. One criterion often analysed is the time to perform the procedure. Although the relevance of the procedures' time is unquestionable from an economic perspective, the analysis alone does not reflect surgical proficiency ${ }^{10}$. Complex laparoscopic tasks, such as laparoscopic sutures and intracorporeal knots, require a high level of technical skill. This can be acquired through the use of a simulation model. In a systematic review, Buckley et al. ${ }^{11}$ studied the acquisition of skills through simulation and transfer to the operating room. Sixteen randomized controlled trials involving 309 participants were eligible for qualitative analysis. Operative time decreased significantly in all studies.

Simulation training programmes have shown a shortening of the transferable learning curve to the operating room, reducing intra and postoperative complications and, consequently, improving surgical outcomes for patients. Aggarwal et al. ${ }^{12}$ studied the learning curve in 20 novice residents using virtual reality simulators for cholecystectomy compared to conventional surgeries in swine. The author concluded that the simulation model was more efficient and reduced the learning curve in the operating room. It should be emphasized, however, that there is still a well-designed teaching model proven to be effective in the preparation of residents for skills acquisition in advanced laparoscopic techniques outside the operating room implemented in surgical residences in Brazil. Nacul et al. ${ }^{1}$ reviewed the situation of teaching in video surgery in services that published their methods in Brazil, concluding that there is a great deficit in the training and training in video surgery in the different specialties, which is reflected in the large learning curves ${ }^{1}$.

\section{Limitations}

The study did not measure the retention of skills after the acquisition of proficiency. New translational studies will be needed to analyse the transfer of skills to the operating room. Residents may have had external training, apart from the training offered, between the initial and final tests, although there wasn't parallel formal training offered in their study places during the study period. Further studies may use concurrent controls of same year.

\section{- Conclusions}

The teaching model, which was the object of this study, presented significant evidence of evolution in the learning curve, offering the beginner surgeon the methods, ability, safety and efficacy in performing basic and advanced tasks in video surgery, such as knots and intracorporeal sutures. Mastery of these skills will enable surgeons to progressively perform more complex procedures. 


\section{References}

1. Nácul MP, Cavazzola LT. Current status of residency training in laparoscopic surgery in Brazil: a critical review. ABCD Arq Bras Cir Dig (São Paulo). 2015;28(1):81-5. doi: 10.1590/s0102-67202015000100020.

2. Stefanidis D, Arora S, Parrack DM, Hamad GG, Capella L, Grantcharov T, Urbach DR, Scott DJ, Jones DB. Research priorities in surgical simulation for the 21st century. Am J Surg. 2012;203(1):49-53. doi: 10.1016/j. amjsurg.2011.05.008.

3. Cabrera Vilanova A, Muñoz García A, Sabench Pereferrer F, Hernández González M, Castillo Déjardin DD. Evaluación de las habilidades quirúrgicas durante el pregrado mediante la introducción de un simulador virtual. Cir Esp (Ed impr). 2013;91(3):17783. doi: 10.1016/j.ciresp.2012.05.019.

4. Buckley CE, Kavanagh DO, Traynor O, Neary PC. Is the skillset obtained in surgical simulation transferable to the operating theatre? Am J Surg. 2014;207(1):146-57. doi: 10.1016/j.amjsurg.2013.06.017.

5. Moura Júnior LGD. Modelo acadêmico de ensino teórico-prático em vídeo cirurgia, por meio de novo simulador real de cavidade abdominal (Doutotado). Universidade Federal do Ceará; 2015.

6. Palter VN, Orzech N, Reznick RK, Grantcharov TP. Validation of a structured training and assessment curriculum for technical skill acquisition in minimally invasive surgery: a randomized controlled trial. An
Surg. 2013;257(2):224-30. doi: 10.1097/ SLA.0b013e31827051cd.

7. Choy I, Okrainec A. Simulation in surgery: perfecting the practice. Surg Clin North Am. 2010;90(3):457-73. doi: 10.1016/j. suc.2010.02.011.

8. Cavalini WLP, Claus CMP, Dimbarre D, Cury Filho EA, Bonin EA, Loureiro Mde P, Salvalaggio P. Development of laparoscopic skills in Medical students naive to surgical training. Einstein (São Paulo). 2014;12(4):467-72. doi: 10.1590/S167945082014 AO3237.

9. Korndorffer JR, Dunne JB, Sierra R, Stefanidis $D$, Touchard CL, Scott DJ. Simulator training for laparoscopic suturing using performance goals translates to the operating room. J Am Coll Surg. 2005;201(1):23-9. doi: 10.1016/j. jamcollsurg.2005.02.021.

10.Berguer R, Forkey D, Smith W. Ergonomic problems associated with laparoscopic surgery. Surg Endosc. 1999;13(5):466-8. doi: 10.1007/PL00009635.

11.Buckley CE, Kavanagh DO, Nugent E, Ryan D, Traynor OJ, Neary PC. The impact of aptitude on the learning curve for laparoscopic suturing. Am J Surg. 2014;207(2):263-70. doi: 10.1016/j.amjsurg.2013.08.037.

12.Aggarwal R, Hance J, Undre S, Ratnasothy J, Moorthy K, Chang A, Darzi A. Training junior operative residents in laparoscopic suturing skills is feasible and efficacious. Surgery. 2006;139(6):729-34. doi: 10.1016/j. surg.2005.12.010.

\section{Correspondence:}

Francisco Ferreira Filho

Centro Universitário Unichristus

Rua João Adolfo Gurgel, 133

60190-060 Fortaleza - CE Brasil

Tel.: (55 85)3265-8100

ferreiraffilho@gmail.com

Received: Sep 15, 2017

Review: Nov 16, 2017

Accepted: Dec 19, 2017
Conflict of interest: none

Financial source: none
${ }^{1}$ Research performed at Laparoscopic Surgery, Centro Universitário Unichristus, and Instituto Dr. José Frota, Fortaleza-CE, Brazil. 